\title{
Modulation of Dopamine Efflux in the Striatum following Cholinergic Stimulation of the Substantia Nigra in Intact and Pedunculopontine Tegmental Nucleus-Lesioned Rats
}

\author{
Charles D. Blaha' ${ }^{1}$ and Philip Winn ${ }^{2}$ \\ 'Departments of Psychology and Psychiatry, University of British Columbia, Vancouver, British Columbia, Canada V6T \\ $1 \mathrm{Z4}$ and ${ }^{2}$ Department of Psychology, University of St. Andrews, St. Andrews, Fife KY16 9JU, United Kingdom
}

\begin{abstract}
The effects of microinjections of cholinergic agents into the substantia nigra pars compacta on dopamine (DA) efflux in the anterior dorsomedial striatum of urethane-anesthetized rats were investigated using in vivo chronoamperometry and intracerebral microdialysis techniques. A dose-dependent augmentation of DA efflux as evidenced by increases in the chronoamperometric signals was observed in the striatum following nigral microinjections of the cholinergic agonists nicotine or carbachol. Enhancing extracellular concentrations of ACh in the substantia nigra by intranigral infusions of the cholinesterase inhibitor neostigmine also resulted in an increase in the chronoamperometric signal corresponding to DA overflow in the striatum. These stimulatory effects of neostigmine on DA efflux in the striatum were confirmed using in vivo microdlalysis. Compared to sham-operated control animals, quinolinic acid lesions of the pedunculopontine tegmental nucleus (PPTg) resulted in an attenuation of the stimulatory effects of intranigral neostigmine on DA efflux in the striatum. In contrast, these treatments resulted in an enhancement of striatal DA efflux in response to nigral infusions of the direct $\mathrm{ACh}$ receptor agonist nicotine. Combined, these data suggest that PPTg cholinergic neurons are indirectly involved in regulating the activity of the striatum by modulating the activity of DA neurons in the substantia nigra of the rat.
\end{abstract}

IKeywords: substantia nigra, striatum, pedunculopontine tegmental nucleus, dopamine, ACh, quinolinate, chronoamperometry, dialysis, rat]

$\mathrm{ACh}$, its synthetic enzyme CAT, and degradative enzyme AChE are all present in the substantia nigra (Jacobowitz and Goldberg, 1977; Lehmann and Fibiger, 1978; Beninato and Spencer, 1987; Beninato and Spencer, 1988), as are muscarinic (Nastuk and Graybiel, 1991) and nicotinic (Clarke et al., 1985) cholinergic receptors. Dopamine (DA)-containing neurons in the pars compacta appear to be the most likely targets for cholinergic activity within substantia nigra. These neurons contain (Butcher and Marchand, 1978; Lehmann and Fibiger, 1978) and release

\footnotetext{
Received Mar. 24, 1992; revised Sept. 2, 1992; accepted Sept. 16, 1992.

This work was supported by the Medical Research Council of Canada Program Grant 23. C.D.B. is a Canadian MRC Scholar. P.W. was supported by the Wellcome Trust. We wish to thank Dr. A. G. Phillips FRSC, Dr. H. C. Fibiger, Roxanne Hopkins, Mary Latimer, Jay Dunbar, and the Photographic Unit, Biology Department, St. Andrews for their advice and technical assistance.

Correspondence should be addressed to Philip Winn at the above address. Copyright (C) 1993 Society for Neuroscience $0270-6474 / 93 / 131035-10 \$ 05.00 / 0$
}

(Greenfield et al., 1980) AChE, and electrophysiological studies show that cholinergic stimulation predominantly excites them through both muscarinic and nicotinic receptors (Kemp et al., 1977; Lichtensteiger et al., 1982; Clarke and Pert, 1985; Clarke et al., 1985; Lacey et al., 1990). Behavioral studies also support the hypothesis that there is an interaction between cholinergic systems and DA-containing neurons in the substantia nigra. Microinjection of carbachol, physostigmine sulfate, or ACh/ physostigmine mixtures into the anterior substantia nigra has been shown to affect motivated behavior in a manner consistent with the stimulation of DA-containing neurons (Winn and Redgrave, 1979, 1981; Winn et al., 1983; Winn, 1991). Feeding in response to cholinergic stimulation has been shown to be blocked by intranigral atropine (Winn et al., 1983) and by low, nonsedative systemic doses of the DA receptor antagonist haloperidol (Taha and Redgrave, 1984), while unilateral 6-hydroxydopamine lesions that deplete the dorsal striatum of $\sim 50 \%$ of its DA content, but spare nucleus accumbens DA, abolish completely the response to unilateral microinjections of carbachol into the ipsilateral substantia nigra (Parker et al., 1991).

Interest in the interaction between $\mathrm{ACh}$ and DA within the substantia nigra has increased following demonstrations using CAT immunohistochemistry of a cholinergic projection to nigra from the pedunculopontine tegmental nucleus (PPTg) and possibly also the laterodorsal tegmental nucleus (LDTN) (Woolf and Butcher, 1986; Beninato and Spencer, 1987, 1988; Clarke et al., 1987; Lee et al., 1988; Scarnati et al., 1988; Gould et al., 1989). There is uncertainty, however, about the exact nature of this connection. Cholinergic synapses are invariably found in the pars compacta, and some authors suggest that the PPTg provides an important cholinergic innervation of the substantia nigra (Woolf and Butcher, 1986; Gould et al., 1989) whereas others suggest that cholinergic innervation of this structure is nonexistent (Lee et al., 1988). However, given that there is no other known cholinergic projection to substantia nigra, this last suggestion appears incompatible with the high density of muscarinic and nicotinic receptors in the pars compacta. It has also been demonstrated recently in the ferret that cholinergic fibers in the substantia nigra wrap around the dendrites of pars compacta DA-containing ncurons and make multiple synaptic contacts (Bolam et al., 1991). Though it is not clear whether these cholinergic fibers derive from PPTg or LDTN neurons, or indeed both, this gives clear evidence of an interaction between cholinergic and dopaminergic systems in the substantia nigra.

Though these data taken all together suggest that there is a cholinergic projection to the substantia nigra from a site caudal 
to it, and that this projection makes synaptic contact with pars compacta DA-containing neurons, no direct evidence shows that increasing cholinergic transmission in the substantia nigra alters DA activity in the ipsilateral striatum. There are now means available to show this. In vivo microdialysis (Ungerstedt, 1984) and in vivo clectrochemical techniques (Adams and Marsden, 1982) can both be used to assess neurochemical activity. There is at present some debate concerning the relative merits of these two techniques, it having been suggested that the extraction properties of microdialysis might adversely affect the baseline extracellular levels of various molecules (Benveniste et al., 1989; Blaha, 1992). In vivo electrochemical techniques in contrast have much less effect on CNS tissue and, if appropriately modified electrodes are used, can be made selective for particular molecular species (Blaha and Lane, 1983; Blaha and Jung, 1991). In the present experiments we have used both of these techniques, though the emphasis has been placed on electrochemical techniques, dialysis being used to validate the measurements made.

The present experiments were designed to test two hypotheses: (1) that cholinergic receptor agonists (either nicotinic or muscarinic) and cholinesterase inhibitors (which increase the level of endogenous $\mathrm{ACh}$ ) will increase striatal DA activity by exciting pars compacta DA-containing neurons, and (2) that lesions in the PPTg will remove the cholinergic input to the substantia nigra and therefore diminish the response to $\mathrm{AChE}$ inhibitors (whose action depends upon the inhibition of hydrolysis of $\mathrm{ACh}$ released from intact cholinergic terminals) but enhance the response to direct ACh receptor agonists because of the development of postsynaptic receptor supersensitivity. We have tested these hypotheses by measuring the interstitial concentration of DA in the dorsomedial striatum using chronoamperometry before and after microinjection of cholinergic agents into the ipsilateral substantia nigra, in intact and in PPTglesioned rats.

\section{Materials and Methods}

Subjects. Male hooded rats (Long-Evans) weighing 250-350 gm were used in all experiments. Animals were housed in individual stainless steel cages at constant room temperature $\left(24^{\circ} \mathrm{C}, 60 \%\right.$ relative humidity $)$ and maintained on a 12:12 hr light/dark cycle (lights on at 07:00). Food and water were available ad libitum.

Electrochemical studies. Rats were anesthetized with urethane (1 gm/ $\mathrm{kg}$, i.p.) and given a single supplemental injection $(0.5 \mathrm{gm} / \mathrm{kg}$, i.p. $)$ to maintain a constant level of anesthesia over the course of each experiment. Body temperature was maintained at $37^{\circ} \mathrm{C}$ with a temperaturecontrolled water heating pad (American Hospital Supplies, McGraw Park, IL). Stearate-modified graphite paste recording electrodes were prepared as previously described (Blaha and Lane, 1983). These electrodes permit in vivo measurement of changes in DA efflux without interference from other oxidizable compounds in brain extracellular fluid (Blaha and Jung, 1991). Recording electrodes were implanted stereotaxically into the anterior dorsomedial striatum (coordinates +2.8 $\mathrm{mm}$ from bregma, $+3.0 \mathrm{~mm}$ lateral to midlinc, and $-4.0 \mathrm{~mm}$ from dura, with the incisor bar $5 \mathrm{~mm}$ above the interaural line; Pellegrino et al., 1979). An $\mathrm{Ag} / \mathrm{AgCl}$ reference and stainless steel auxiliary electrode combination was placed in contact with contralateral cortical tissue. Repetitive chronoamperometric measurements were conducted with an electrometer (Echempro, Vancouver, Canada). Efflux of DA was monitored by applying a potential pulse for $1 \mathrm{sec}$ from $-0.15 \mathrm{~V}$ to +0.25 $\mathrm{V}$ versus $\mathrm{Ag} / \mathrm{AgCl}$ to the recording electrode at $30 \mathrm{sec}$ intervals and monitoring the DA oxidation current at the end of each $1 \mathrm{sec}$ pulse. Changes in DA efflux in the dorsomedial striatum observed following drug administration were expressed as a percentage change from baseline and were derived as follows. The baseline current recorded by chronoamperometry includes both Faradaic and residual (background) current. As previously described (Blaha et al., 1990; Blaha and Phillips,
1992), the Faradaic component corresponding to DA oxidation in the dorsomedial striatum was determined by measurement of the maximal decrease in DA oxidation currents from baseline levels following administration of $\gamma$-hydroxybutyric acid lactone (GBL) $(750 \mathrm{mg} / \mathrm{kg}$, i.p.). GBL administration decreased DA oxidation values in the striatum by $-0.83 \pm 0.04 \mathrm{nA}(100 \pm 5 \%)$. This mean current value (100\% baseline control) thus provided a reference from which to computc percentage increases in DA oxidation current following drug administration. Other techniques used for estimating baseline DA oxidation current values yield similar values [tetrodotoxin, $-0.78 \pm 0.02 \mathrm{nA}$ (Blaha and Phillips, 1992); side-by-side microdialysis and chronoamperometry, $-0.83 \pm$ $0.05 \mathrm{nA}$ (Blaha, 1992)]. Drug-induced changes in DA oxidation current were calculated as absolute current values taken from the preinjection baseline of each drug to the observed peak effect and expressed as a percentage change with respect to the mean baseline current value given above.

Microdialysis studies. Rats were anesthetized with urethane and mounted in a stereotaxic frame, and body temperature was maintained as described above. A single dialysis probe was implanted the dorsomedial striatum (coordinates $+2.8 \mathrm{~mm}$ from bregma, $+2.8 \mathrm{~mm}$ lateral to midline, and $7.0 \mathrm{~mm}$ from dura, with the incisor bar $5 \mathrm{~mm}$ above the interaural line; Pellegrino et al., 1979). The dialysis probe was of the concentric design consisting of a semipermeable membrane (exposed membrane length, $4 \mathrm{~mm}$; o.d., $340 \mu \mathrm{m}$ wet; $64,000 \mathrm{MW}$ cutoff; Filtral 12, Hospal-gambro Inc.), PE5O inlet tubing, and fused silica/PE10 outlet tubing (Pfaus et al., 1990). The probe was perfused continuously with Ringer's solution (1.5 mM Na-phosphate buffer containing $147 \mathrm{~mm}$ $\mathrm{NaCl}, 3 \mathrm{~mm} \mathrm{KCl}, 1 \mathrm{~mm} \mathrm{MgCl}$, and $1.3 \mathrm{mM} \mathrm{CaCl}_{2} ; \mathrm{pH} 7.3$ ) at $5 \mu \mathrm{l} / \mathrm{min}$ using a microinfusion pump (Harvard Pump 22). On-line HPLC analysis of DA in dialysate samples was performed using the method of Damsma et al. (1990). Briefly, dialysate samples from the probe were automatically injected onto an HPLC column $(150 \times 4.8 \mathrm{~mm}$, Nucleosil 5-C18) at $10 \mathrm{~min}$ intervals via an automatic sample valve (Valco Instrument Co. Inc., model EQ36) controlled by an adjustable timer (Valco). Mcasurement of DA in each $50 \mu$ l dialysate sample was quantified by HPLC with electrochemical detection (HPLC-EC). The mobile phase was delivered by a dual-piston pump (Bio-Rad) at $1.5 \mathrm{ml} / \mathrm{min}$ and consisted of $0.1 \mathrm{M}$ acetic acid (adjusted to $\mathrm{pH} 4.1$ with $\mathrm{Na}$-acetate), 0.01 mM $\mathrm{Na}_{2}$ EDTA, $0.5 \mathrm{~mm}$ sodium octyl sulfate, and $150 \mathrm{ml}$ methanol/ liter. Detection of striatal DA was achieved by sequential oxidation and reduction of dialysate samples via a coulometric/amperometric analytical cell (coulometric electrode, $+0.35 \mathrm{~V}$; amperometric electrode, -0.25 $\mathrm{V}$; ESA, model 5011). Chromatograms were displayed on a dual pen strip-chart recorder (Kipp). The detection limit of DA on the ESA system was $6 \mathrm{fmol} /$ injection. Basal and stimulated values for DA are presented in terms of percentage change with respect to the average of the last three stable samples $(100 \%$ baseline, uncorrected for probe recovery) prior to treatment.

Drug microinjections. Drug solutions were backloaded into a 30 gauge stainless steel cannula $\left(90^{\circ}\right.$ bevel) connected via PE10 tubing to a $5 \mu \mathrm{l}$ microsyringe (SGE) mounted in an infusion pump (Sage Instruments). Following stable baseline recordings of at least $60-120 \mathrm{~min}$ in both chronoamperometric or dialysis experiments, the infusion cannula was inserted in graduated steps over a $15 \mathrm{~min}$ period into the substantia nigra pars compacta (coordinates $-2.8 \mathrm{~mm}$ from bregma, $+2.0 \mathrm{~mm}$ lateral to midline, and $-8.0 \mathrm{~mm}$ from dura, with the incisor bar $5 \mathrm{~mm}$ above the interaural line; Pellegrino et al., 1979) ipsilateral to the in vivo recording electrode or dialysis probe. Following a further $10 \mathrm{~min}$ baseline recording, either neostigmine $(0.25$ or $0.5 \mathrm{~mm})$, nicotine $(0.5$ or $5.0 \mathrm{~mm})$, or carbachol $(0.5$ or $5.0 \mathrm{~mm}$ ) was injected into the substantia nigra in a volume of $0.5 \mu \mathrm{l}$ over $2 \mathrm{~min}$. Infusion of $0.5 \mu \mathrm{l}$ saline $(0.9 \%$ $\mathrm{NaCl}$ ) served as the vehicle control. The progress of each microinjection was monitored by noting the movement of a small air bubble placed in the PE10 line. Ten minutes after the infusion, the cannula was slowly retracted from the tissue.

Excitotoxic lesions of the PPIg. Unilateral lesions of the PPTg were made in six rats. Rats were anesthetized with sodium pentobarbital (Somnotol; $30 \mathrm{mg} / \mathrm{kg}$ ) and placed in a stereotaxic frame. Injections of quinolinic acid were made with a $1 \mu$ l syringe ( $\mathrm{SGE}$ ) mounted on the stereotaxic frame. Care was taken to ensure that the beveled face of the needle always pointed rostrally. Two injections were made into the PPTg at the following stereotaxic coordinates: (1) anterior-posterior $+0.8 \mathrm{~mm}$ from interaural line, lateral $+1.6 \mathrm{~mm}$ from midline, and ventral -7.0 $\mathrm{mm}$ from skull surface; and (2) anterior-posterior $+1.5 \mathrm{~mm}$ from interaural line, $\pm 1.7 \mathrm{~mm}$ from midline, and ventral $-7.5 \mathrm{~mm}$ from skull surface, with the skull level (Paxinos and Watson, 1986). The infusions 


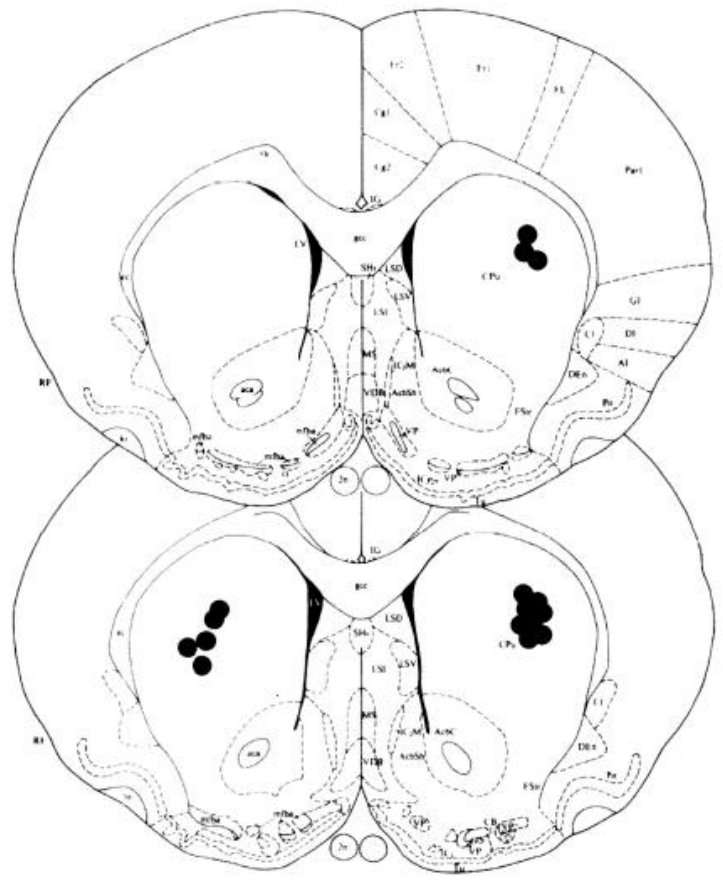

Dialysis Chronoamperometry

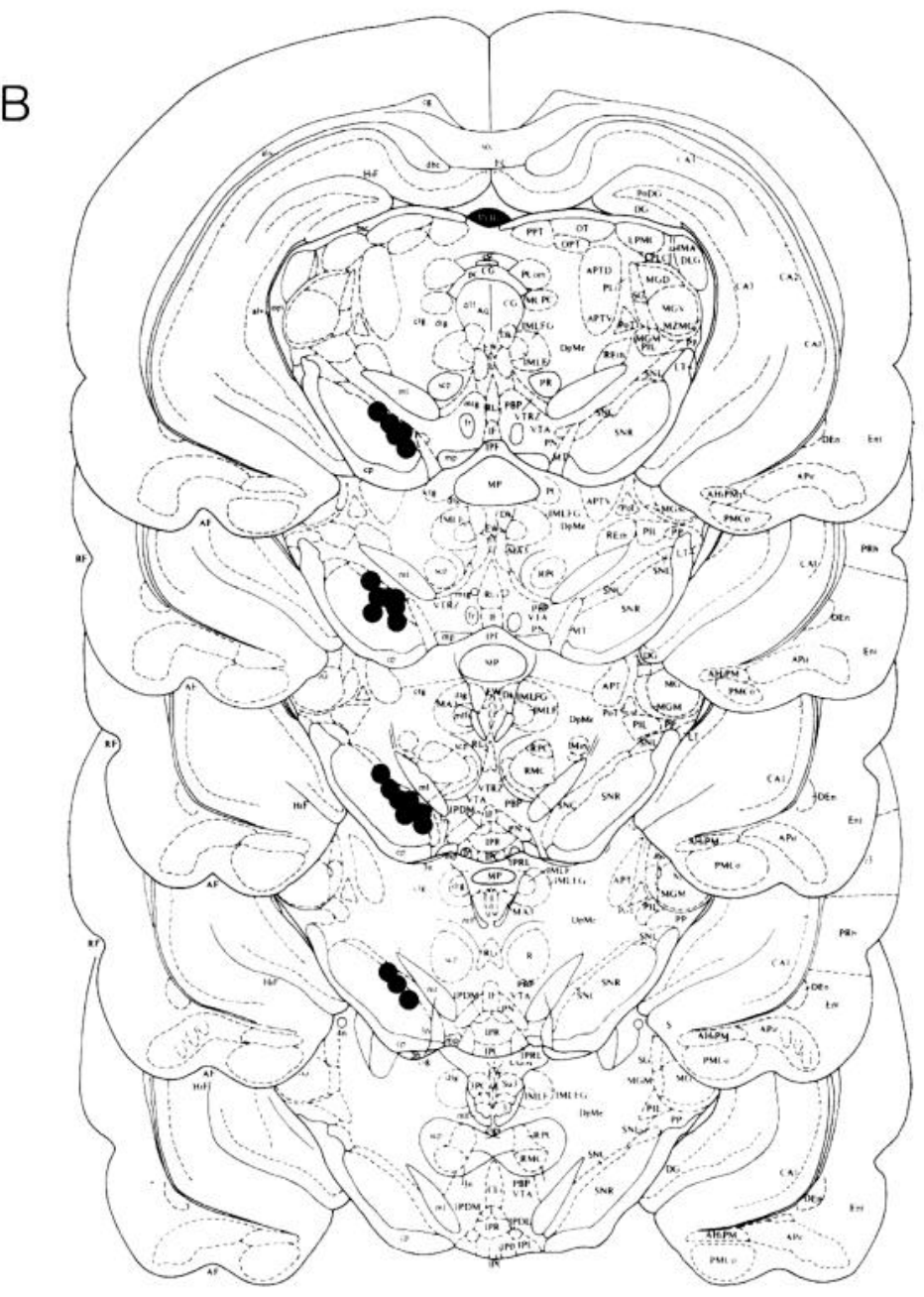

Figure 1. A, Representative sections showing the placement of electrochemical electrodes and microdialysis probes in the striatum; $B$, representative sections showing the placement of microinjection cannulas in the substantia nigra. Sections were redrawn from the atlas of Paxinos and Watson (1986).

were made using a step-down procedure of $0.02 \mu$ l every $10 \mathrm{sec}$ with an additional $300 \mathrm{sec}$ in situ to allow for toxin diffusion prior to retraction of the needle. At each site in the PPTg, rats received an injection of $24 \mathrm{nmol}(0.2 \mu \mathrm{l} \times 0.12 \mathrm{M})$ of quinolinic acid; this dose was chosen as a result of previous experiments (Rugg et al., 1992; Dunbar et al., 1992). Quinolinate was dissolved in phosphate buffer ( $\mathrm{pH} 7.4)$ and the final $\mathrm{pH}$ of the solution adjusted with $2 \mathrm{M} \mathrm{NaOH}$ to 7.2. Control rats were injected with phosphate buffer vehicle only $(n=3)$. Rats were observed in the immediate postoperative period, and excitotoxic lesions were followed by postural deviation, barrel rolling, forepaw treading, and rotation. These generally lasted for $<2 \mathrm{hr}$, and when convulsive activity had stopped rats were returned to the home cage room. Determination of DA efflux in the dorsomedial striatum in response to nigral cholinergic stimulation was examined in these rats, using the normal procedures, 14-33 d after the lesions had been made. Three PPTglesioned rats were tested with intranigral nicotine $(0.05 \mathrm{~mm})$ and three with intranigral neostigmine $(0.25 \mathrm{~mm})$; three sham-lesioned rats were also tested with intranigral neostigmine $(0.25 \mathrm{~mm})$.

Chemicals. Dopamine hydrochloride, carbamylcholine chloride (carbachol), nicotine hydrogen (+)-tartrate, and neostigmine methylsulfate were obtained from the Sigma Chemical Co. Quinolinic acid was obtained from Research Biochemicals, Inc. All other chemicals of reagent or analytical grade quality were purchased from various commercial sources.

Histological analysis. After completion of each acute experiment, the rats brain was removed and placed in $10 \%$ buffered formalin. After fixation, $40 \mu \mathrm{m}$ sections were cut on a bench microtome and stained for Nissl substance with cresyl violet. The placements of electrochemical recording electrodes, microdialysis probes, and nigral cannulas were determined using a Leitz Diaplan microscope. The positions of quinolinate lesions in the PPTg were also determined from $40 \mu \mathrm{m}$ sections stained with cresyl violet. Silhouettes of lesions were drawn (by a colleague blind with respect to lesion condition) onto representative sections of the rat brain (Paxinos and Watson, 1986) with the aid of a drawing tube fitted to the microscope.

Statistical analysis. Statistical analysis of data was performed using a one-way analysis of variance (ANOVA) for repeated measures of time with drug effects. When the ANOVA indicated a significant effect, a Tukey post hoc test was used to compare drug-induced changes in striatal DA efflux with respect to saline-treated controls or quinolinatelesioned groups at postinfusion time points indicated below. A value of $P<0.01$ was selected as indicating statistical significance. Variability was expressed as the mean $( \pm$ SEM).

\section{Results}

\section{Cannula and electrode placements}

Figure 1 shows the placements of nigral cannulas (Fig. $1 B$ ) and the location of the tips of the electrochemical electrodes and microdialysis probes (Fig. $1 A$ ). It is clear that all of these nigral and striatal placements were in similar situations, and that differences between placements cannot account for any differences present in the data presented below. 

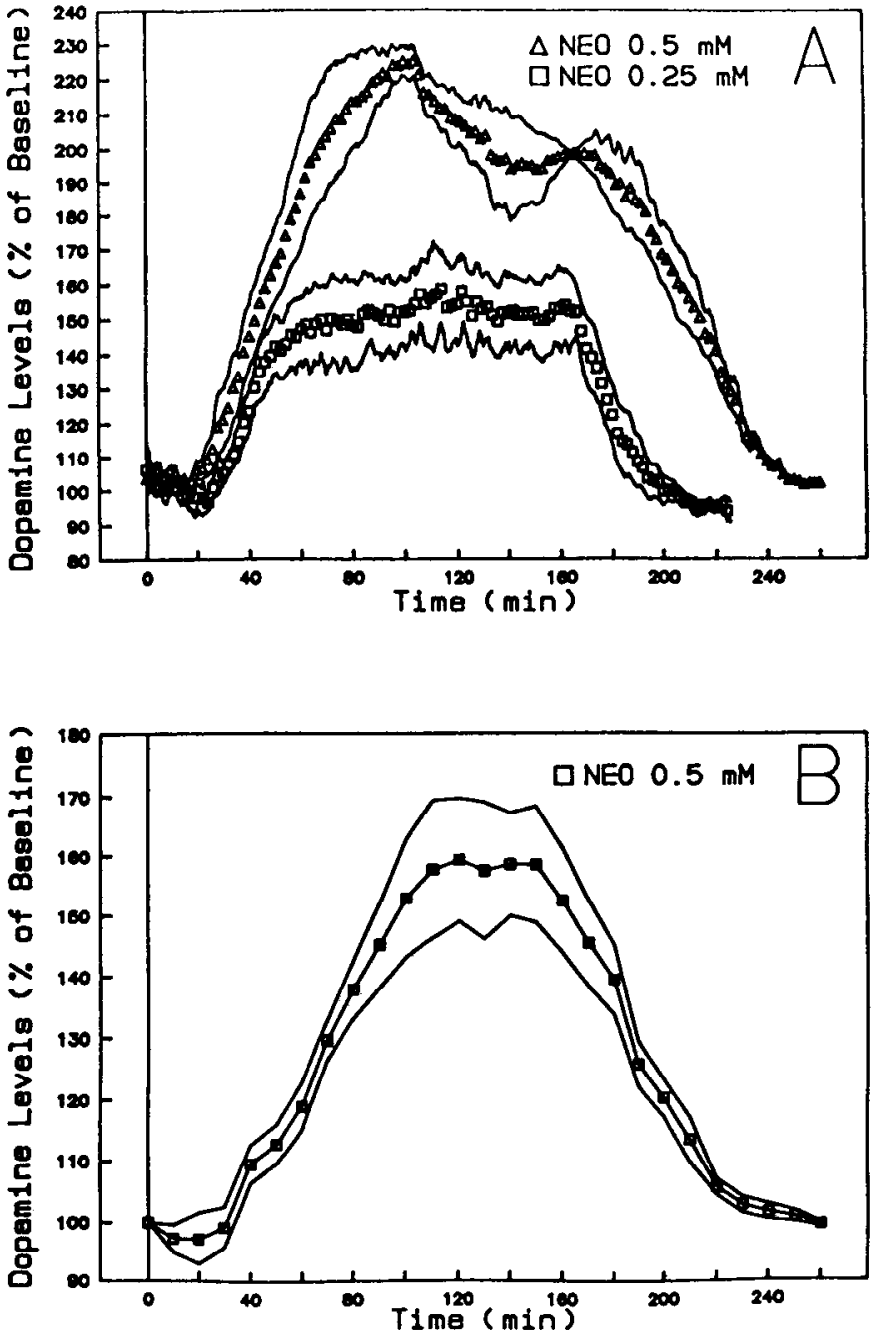

Figure 2. A, Chronoamperometric recordings depicting the time courses of the stimulatory effects of intranigral infusions of $0.25 \mathrm{~mm}$ and 0.5 mM neostigmine (NEO) on DA efflux in the dorsomedial striatum. Effects were significant $(P<0.01)$ between postinfusion intervals of 40 $180 \mathrm{~min}$ and $40-230 \mathrm{~min}$, respectively. $B$, Effects of intranigral infusion of $0.5 \mathrm{~mm}$ neostigmine on the levels of $\mathrm{DA}$ in dialysate samples taken every 10 min from the striatum. Points represent the mean changes in the chronoamperometric responses $(n=3)$ and dialysate DA concentrations $(n=5)$. Solid lines represent the SEM. Changes in DA efflux determined by each technique differed significantly $(P<0.01)$ between postinfusion intervals of $40-230 \mathrm{~min}$. Chronoamperometric responses at 2 min intervals are presented for clarity.

\section{Effects of neostigmine, nicotine, and carbachol on DA efflux in} the dorsomedial striatum

As shown in Figure $2 A$, microinjection of the AChE inhibitor neostigmine into the substantia nigra increased the chronoamperometric signals corresponding to DA efflux in the anterior dorsomedial striatum. The onset latencies for these effects were 30 and $25 \mathrm{~min}$ for the neostigmine doses of 0.25 and $0.5 \mathrm{~mm}$, respectively. DA efflux in the striatum reached maximal increases of $144 \pm 10 \%$ and $227 \pm 6 \%$ (Table 1) with respect to baseline levels $(0.83 \mathrm{nA}, 100 \%)$ within 60 and $100 \mathrm{~min}$, respectively, following injection of neostigmine. The total durations of action for these effects were 210 and $250 \mathrm{~min}$ for 0.25 and $0.5 \mathrm{mM}$, respectively. These temporal profiles are in agreement with the known duration of cholinesterase inhibition by neostigmine (Goodman-Gilman et al., 1980). A similar tem poral profile was observed for changes in DA concentrations measured in striatal dialysate samples following substantia nigra microinjection of neostigmine at the dose of $0.5 \mathrm{~mm}$ (Fig. $2 B$ ). Similar to results obtained using chronoamperometry, this dose of neostigmine produced maximal increases in DA efflux within $110 \mathrm{~min}$ with a total duration of action of $250 \mathrm{~min}$. However, in comparison with the maximal increase of $227 \%$ observed using chronoamperometry, dialysate DA increased only to a level of $159 \pm 11 \%$ with respect to preinjection baseline control values (Fig. $2 A, B$; Table 1 ).

Microinjection of the cholinergic receptor agonist nicotine into the substantia nigra resulted in pronounced and prolonged increases in chronoamperometric signals recorded in the dorsomedial striatum (Fig. 3A,B; Table 1). Maximal increases in striatal DA efflux of $155 \pm 12$ and $512 \pm 55 \%$ were observed within 90 and $130 \mathrm{~min}$ following microinjection of nicotine into the substantia nigra at doses of 0.5 and $5.0 \mathrm{~mm}$, respectively. These facilitatory effects of nicotine on striatal DA efflux were sustained over the course of the chronoamperometric experiment (250-300 min). Microinjection of the muscarinic receptor agonist carbachol also resulted in robust and sustained increases in the chronoamperometric signals recorded in the striatum. Carbachol injections at the doses of 0.5 and $5.0 \mathrm{~mm}$ resulted in maximal increases in striatal DA efflux of $132 \pm 4 \%$ and 331 $+18 \%$ within 60 and $160 \mathrm{~min}$, respectively (Fig. $4 A, B$; Table 1). DA efflux remained significantly elevated above baseline levels over the course of these experiments (210-250 $\mathrm{min})$. The facilitatory effects of substantia nigra microinfusions of neostigmine, nicotine, and carbachol on DA efflux in the dorsomedial striatum appear specific, as comparable substantia nigra microinjections of drug vehicle $(0.9 \%$ saline) failed to alter significantly the chronoamperometric baseline in the dorsomedial striatum recorded over similar time periods (Fig. 4A, Table 1).

\section{Effects of PPTg lesions}

Figure 5 shows silhouettes of the largest and smallest lesions made by quinolinate in the PPTg. In every case a significant portion of the PPTg was destroyed, and the lesions were similar to those reported previously in which significant numbers of cholinergic neurons were lost from the PPTg but not the adjacent LDTN (Rugg et al., 1992; Dunbar et al., 1992). Damage was present from the caudal PPTg, on the lateral tip of the superior cerebellar peduncle, down through its length to the caudal edge of the substantia nigra. No significant damage was present in the substantia nigra, though neurons were lost from other structures adjacent to the PPTg, including the deep mesencephalic nucleus, cuneiform nucleus, and retrorubral nucleus. The damage to these structures varied between rats, and none of the structures was ever completely lesioned. It is unlikely, therefore, that this partial and inconsistent damage will have significantly affected the results of these experiments. Reactive gliosis was present in all lesioned tissue, as noted previously (Rugg et al., 1992; Dunbar et al., 1992).

As shown in Figure 6A, microinjection of $0.25 \mathrm{~mm}$ neostigmine into the substantia nigra of PPTg-lesioned rats resulted in an attenuated increase in the chronoamperometric signals in the dorsomedial striatum as compared to the neostigmine-induced increases in striatal DA efflux observed in intact control rats. Sham-operated control rats did not differ significantly in their response to a substantia nigra microinjection of neostigmine 


\begin{tabular}{|c|c|c|c|c|c|}
\hline $\begin{array}{l}\text { Drug } \\
\text { treatment }\end{array}$ & Dose (mM) & $\begin{array}{l}\text { Maximal change } \\
\text { in current (nA) }\end{array}$ & $\begin{array}{l}\text { Change from } \\
\text { baseline }(100 \%)\end{array}$ & $\begin{array}{l}\text { Time } \\
(\text { min) }\end{array}$ & $N$ \\
\hline SAL & 150 & $\begin{array}{l}-0.01 \pm 0.04 \\
+0.01 \pm 0.04 \\
-0.01 \pm 0.02 \\
-0.02 \pm 0.03 \\
+0.03 \pm 0.03 \\
-0.02 \pm 0.04 \\
+0.02 \pm 0.05\end{array}$ & $\begin{aligned} 99 & \pm 5 \\
101 & \pm 5 \\
99 & \pm 2 \\
98 & \pm 3 \\
103 & \pm 3 \\
98 & \pm 5 \\
102 & \pm 6\end{aligned}$ & $\begin{array}{r}60 \\
90 \\
100 \\
120 \\
130 \\
150 \\
160\end{array}$ & 4 \\
\hline NEO & 0.25 & $+0.37 \pm 0.08$ & $144 \pm 10^{*}$ & 60 & 3 \\
\hline NEO & 0.5 & $+1.05 \pm 0.05$ & $227 \pm 6^{*}$ & 100 & 3 \\
\hline NEO-DIA & 0.5 & & $159 \pm 11^{* * *}$ & 110 & 5 \\
\hline NEO-LES & 0.25 & $+0.17 \pm 0.03$ & $120 \pm 4^{* *}$ & 150 & 3 \\
\hline NIC & 0.5 & $+0.46 \pm 0.10$ & $155 \pm 12^{*}$ & 90 & 3 \\
\hline NIC & 5.0 & $+3.42 \perp 0.46$ & $512 \pm 55^{*}$ & 130 & 3 \\
\hline NIC-LES & 0.5 & $+0.73 \pm 0.06$ & $188 \pm 7^{* *}$ & 120 & 3 \\
\hline CAR & 0.5 & $+0.27 \pm 0.03$ & $132+4 *$ & 60 & 3 \\
\hline CAR & 5.0 & $+1.92 \pm 0.15$ & $331 \pm 18^{*}$ & 160 & 3 \\
\hline
\end{tabular}

Data are the mean ( \pm SEM) maximal changes in DA oxidation current measured from pre-drug injection baseline values normalized to zero current, which were used to compute mean $( \pm S E M)$ percentage changes in DA efflux with respect to $100 \%$ baseline DA oxidation current values $(0.8 \mathrm{nA})$ (see text for details) at postinfusion time intervals corresponding to maximal effects of each drug (neostigmine, NFO; nicotine, NIC; or carbachol, CAR). SAL, saline. DIA, microdialysis; LES, lesioned.

* Significant $(P<0.01)$ drug-induced percentage changes in baseline versus saline (SAL) values at corresponding post infusion time intervals.

** Significant $(P<0.01)$ differences between drug-induced percentage changes in baseline in PPTg quinolinate-lesioned (NEO-LES and NIC-LES) animals versus nonlesioned animals (NEO and NIC), respectively.

**** Significant $(P<0.01)$ differences between the maximum effects of $0.5 \mathrm{~mm}$ neostigmine on baseline striatal levels of $\mathrm{DA}$ as determined by microdialysis (NEO-DIA) versus chronoamperometry (NEO).

compared to intact controls (peak neostigmine-induced increases in striatal DA efflux $60 \mathrm{~min}$ postinfusion corresponded to $148 \pm 15 \% ;+0.40 \pm 0.12 \mathrm{nA}, n=3$; data not shown). The onset latencies for neostigmine-induced effects were also markedly extended from $30 \mathrm{~min}$ for controls to $60 \mathrm{~min}$ for PPTglesioned animals. DA efflux in the striatum of PPTg-lesioned rats reached maximal increases of $120 \pm 4 \%$ within $150 \mathrm{~min}$ following injection of neostigmine (Table 1). The total duration of action for these effects was similar to those observed in intact animals ( $220 \mathrm{~min}$; Fig. $6 \mathrm{~A}$ ). In contrast to the attenuating effects of PPTg lesions on neostigmine-induced efflux of striatal DA, substantia nigra microinfusions of $0.5 \mathrm{~mm}$ nicotine resulted in an augmentation of the chronoamperometric response in lesioned animals. Maximal increases in striatal DA efflux of 188 $\pm 7 \%$ were observed within 120 min following microinjection of nicotine into the substantia nigra of PPTg-lesioned rats (Fig. $6 B$, Table 1). As in the case of control animals, DA efflux in the dorsomedial striatum remained elevated over the course of the chronoamperometric experiment (240 min).

\section{Discussion}

\section{Nigral $A C h$ and striatal $D A$}

The data presented here show that cholinergic stimulation of the anterior substantia nigra increased the concentration of DA in the extraccllular space of the dorsomedial striatum. Both nicotinic and muscarinic receptor agonists did this, and although full dose-effect curves were not established, nicotine appeared to be the more potent of the two. Neostigmine also produced a clear effect that was presumably dependent on the inhibition of $\mathrm{AChE}$ activity and consequent potentiation of the effects of endogenous $\mathrm{ACh}$ released from terminals in the substantia nigra.
These data are consistent with the observation that pars compacta neurons contain AChE (Butcher and Marchand, 1978; Lehmann and Fibiger, 1978), which presumably functions normally to inactivate a cholinergic input, and they are consistent also with electrophysiological data showing that both nicotinic and muscarinic agonists excite pars compacta neurons (Clarke et al., 1987; Lacey et al., 1990). The present data also are in agreement with psychopharmacological data suggesting that cholinergic drugs excite pars compacta DA-containing neurons (Winn and Redgrave, 1979, 1981; Taha and Redgrave, 1980; Winn et al., 1983; Parker et al., 1991; Winn, 1991).

\section{In vivo dialysis and electrochemical measurement of changes in striatal DA concentration}

Although evidence for the facilitatory action of neostigmine on nigrostriatal DA neuronal transmission was provided by both electrochemical and microdialysis techniques, the results differed somewhat in terms of the maximum percentage increase in DA efflux. For example, following intranigral infusion of neostigmine $(0.5 \mathrm{~mm})$, a maximum increase in striatal DA efflux reached $159 \%$ with microdialysis as compared to $227 \%$ with chronoamperometry (see Fig. $2 A, B$; Table 1).

Differences between these two techniques in terms of the area of tissue sampled, sampling intervals, and proportion of basal extracellular DA sensitive to TTX following probe implantation into tissue may account for some of the observed discrepancies. For example, the surface area of the cylindrical $4 \mathrm{~mm} \times 0.34$ $\mathrm{mm}$ dialysis probe $\left(427 \times 10^{-4} \mathrm{~cm}^{2}\right)$ exposed to striatal tissue is approximately 240 times greater than that of the area of the $\sim 0.15 \mathrm{~mm}$ (o.d.) planar surface of the electrochemical electrode $\left(1.8 \times 10^{-4} \mathrm{~cm}^{2}\right)$. Thus, in comparison to the electrochemical 

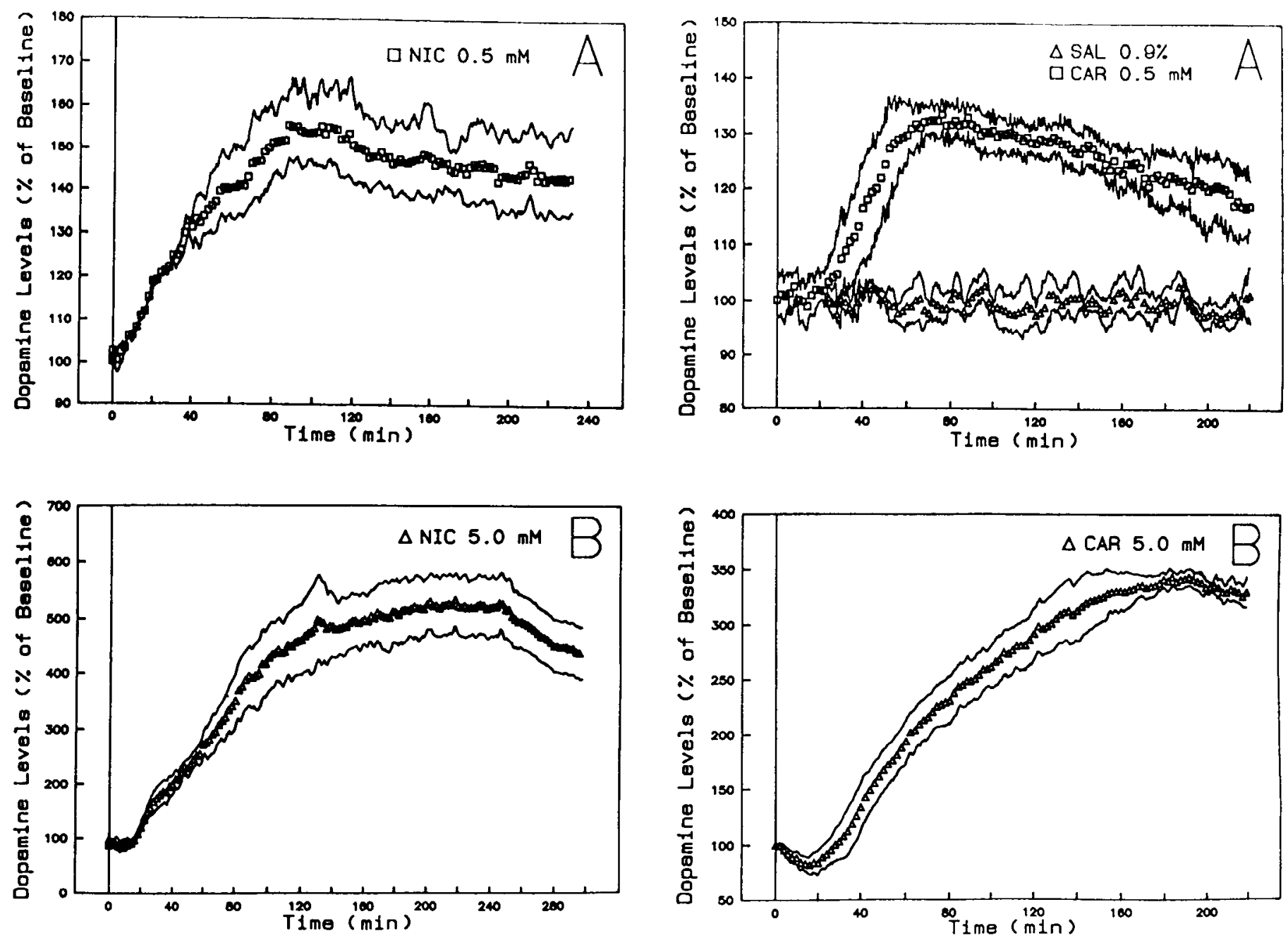

Figure 3. Chronoamperometric recordings depicting the time courses of the effects of intranigral injections of $0.5 \mathrm{mM}(A)$ and $5.0 \mathrm{mM}(B)$ nicotine $(N I C)$ on DA cfflux in the dorsomedial striatum. Points represent the mean changes in the chronoamperometric responses, and solid lines, the SEM. Effects achieved significance $(P<0.01) 20$ and 30 min following drug infusion, respectively. For clarity, only chronoamperometric measurements taken at $2 \mathrm{~min}$ intervals are shown.

electrode, the larger surface area of the dialysis probe results in a relatively greater volume of the striatum sampled by the dialysis method. In this regard, it is worth noting that DA innervation of striatum from the substantia nigra runs a dorsoventralrostrocaudal gradient that is reflected by a similar gradient in striatal tissue content of DA (Glowinski et al., 1966). Given the neurochemical heterogeneity of the striatum, the response of the nigrostriatal DA system to nigral cholinergic stimulation may also show a degree of pharmacological heterogeneity. Additionally, HPLC-EC measurements of individual dialysate samples represent a change in extracellular DA concentrations integrated over the entire intersampling period of $10 \mathrm{~min}$, whereas individual chronoamperometric measurements represent changes integrated over a much smaller sampling period (30 sec).

Recent findings indicate that the baseline DA signals detected by each method differ in TTX sensitivity. Under similar experimental conditions, dialysate DA levels have been shown to exhibit a reduction of $75 \%$ following local TTX administration,

Figure 4. Chronoamperometric recordings showing the time courses of the stimulatory effects of intranigral injections of $0.5 \mathrm{mM}(A)$ and 5.0 $\mathrm{mM}(B)$ carbachol $(C A R)$ on DA cfflux in the dorsomedial striatum. Effects were significant $(P<0.01) 40 \mathrm{~min}$ following CAR infusion at each dose tested. Note the lack of effect of intranigral injections of the drug vehicle ( $S A L ; 0.9 \%$ saline) on the baseline chronoamperometric response recorded in the striatum $(A)$. Points represent the mean changes in the chronoamperometric responses, and solid lines, the SEM. For clarity, only chronoamperometric measurements taken at 2 min intervals are presented.

indicating that at least $25 \%$ of the dialysate DA baseline signal is non-neuronally mediated (Blaha, 1992). In contrast, striatal DA baseline levels determined by in vivo chronoamperometry exhibited complete TTX sensitivity. The precise hasal level of extracellular DA present in the striatum is a matter of considerable controversy. A number of microdialysis studies have estimated basal DA concentration here at between 0.01 and $0.05 \mu \mathrm{M}$, while electrochemical experiments have yielded values between 0.025 and $1.0 \mu \mathrm{M}$. Recent in vitro examinations of the properties of dialysis probes have, however, suggested that these probes significantly reduce the concentrations of dialyzable substances in the surrounding extracellular fluid (Benveniste et al., 1989). The extraction properties of microdialysis may therefore contribute to a significant reduction in the apparent basal concentrations of dialyzed substances, which may explain why microdialysis estimates of basal interstitial concentrations are much lower than those measured by in vivo electrochemical tech- 


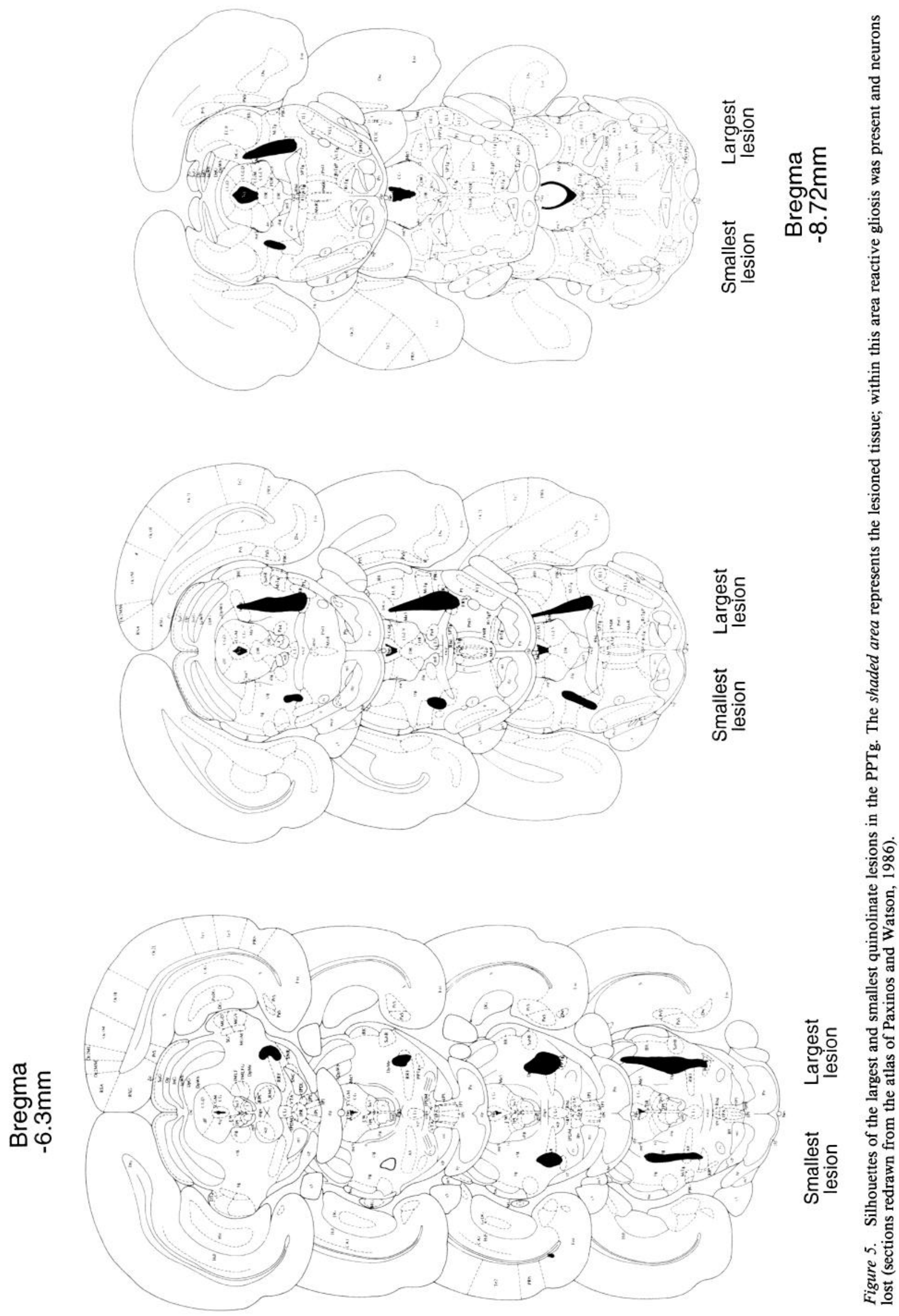



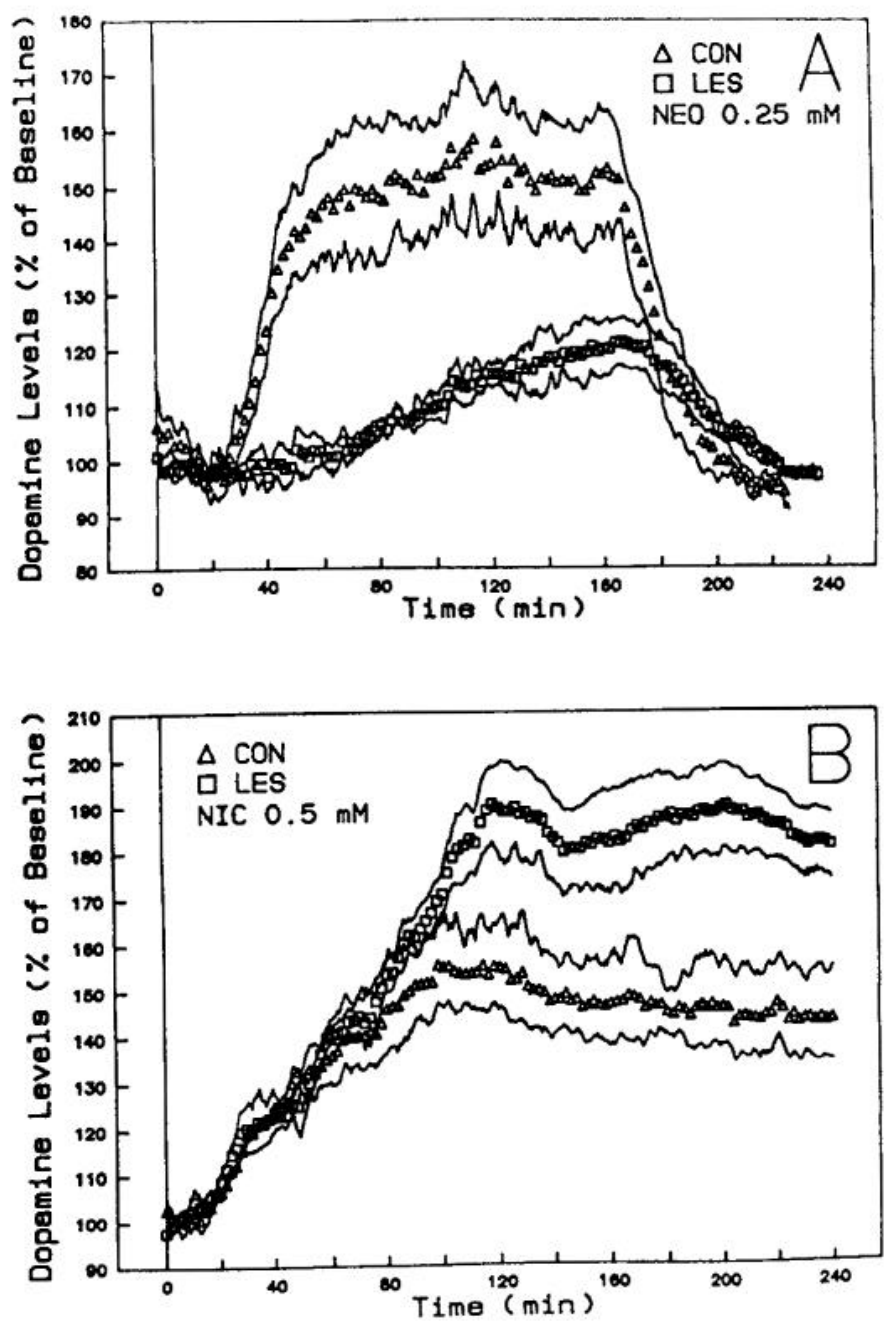

Figure 6. Chronoamperometric recordings showing the time courses of the stimulatory effects of intranigral injections of $0.25 \mathrm{~mm}$ neostigmine $(A)$ and $0.5 \mathrm{~mm}$ nicotine $(B)$ on DA efflux in the dorsomedial striatum before $(C O N)$ and after $(L E S)$ quinolinic acid lesions of the PPTg. Points represent the mean changes in the chronoamperometric responses, and solid lines, the SEM. Effects of neostigmine $(L E S)$ and nicotine $(L E S)$ differed significantly $(P<0.01)$ from drug effects in nonlesioned animals between postinfusion intervals of $40-160$ and 120 $240 \mathrm{~min}$, respectively. Chronoamperometric responses at $2 \mathrm{~min}$ intervals are presented for clarity.

niques. Given the technical and methodological differences between dialysis and in vivo electrochemical techniques, and the fact that the striatum is heterogeneously populated with DA terminals, it is perhaps not too surprising that some differences in the profiles of the magnitude of the effects of neostigmine were observed. Apart from the above differences, the results obtained with the two techniques are complementary and indicate that endogenous cholinergic stimulation of the substantia nigra leads to an augmentation of DA neurotransmission in the striatum.

\section{PPTg and substantia nigra}

Considerable controversy has surrounded the identification of a cholinergic input to the substantia nigra, principally because of the mismatch in the volumes of ACh, CAT, and AChE present. This mismatch is probably accounted for by $\mathrm{AChE}$ having two separate functions: membrane-bound $\mathrm{AChE}$ hydrolyzes $\mathrm{ACh}$ whereas released AChE may have a noncholinergic function (Greenfield, 1980). Studies using CAT immunohistochemistry have demonstrated that a cholinergic projection to substantia nigra originates in the PPTg, and possibly the LDTN, although the nature of this projection has been disputed (Woolf and Butcher, 1986; Lee et al., 1988; Gould et al., 1989). The present data are consistent with the hypothesis that the PPTg makes a significant cholinergic innervation of the pars compacta. Previous work established that quinolinate lesions of the PPTg made in the same way as here reduce the number of CATpositive neurons in the PPTg by $\sim 75 \%$ (Dunbar et al., 1992). Other excitotoxins also reduced the number of CAT-positive neurons, but quinolinate differed from them in having less impact on noncholinergic neurons in this area (Rugg et al., 1992; Dunbar et al., 1992). That these lesions had an effect on a cholinergic projection to the substantia nigra is confirmed by the significant reduction in the striatal DA response to intranigral neostigmine, an agent that acts presynaptically. Had there been no cholinergic projection to the substantia nigra from the PPTg, or had the projection been noncholinergic, the response to neostigmine would not have been affected. Moreover, the fact that responses to nicotine were enhanced suggests that postsynaptic receptor supersensitivity had developed, strengthening the argument in favor of a cholinergic input to nigra from the PPTg having been destroyed. It is also of interest to note that the fact that responses to neostigmine were so affected, and the fact that supersensitivity developed, suggest that the bulk of the cholinergic projection to nigra comes from the PPTg. The LDTN was not affected by lesions placed in the PPTg: had there been a significant innervation from this site, it is unlikely that the lesion-induced effects would have been so great. Chronoamperometric studies examining the effects of specific LDTN lesions in the present paradigm would further clarify this issue.

The PPTg is one of very few extrastriatal sources of nigral innervation able to excite pars compacta DA-containing neurons. While the functions of the PPTg have not been systematically investigated in any detail, most authors agree that these cholinergic neurons are part of the ascending reticular activating system (Mesulam et al., 1989; Harrison et al., 1990). A number of studies suggest that they may have a role in the maintenance of sleep and arousal (Harrison et al., 1990; Semba et al., 1990), and that in particular they may help regulate the state of the thalamus, shifting it from burst-firing to single-spiking modes of operation (Steriade and Llinas, 1988; Steriade et al., 1990). The present data are not inconsistent with the hypothesis that the cholinergic neurons of the PPTg are involved in the maintenance of sleep and arousal, but they further suggest that, as well as regulating the operational state of the thalamus, they may control the basal firing of nigrostriatal DA neurons in order to regulate activity in the striatum. These processes are likely to be functionally related: the active waking state requires not only appropriate thalamocortical activity, but also an operational basal ganglia. Further studies will concentrate on elucidating the neurochemical consequences of the action of ACh in the substantia nigra, and on defining the behavioral processes that these cholinergic neurons influence.

It has been known for some time that cholinergic neurons are lost from the PPTg, and possibly the LDTN, in Parkinson's disease and supranuclear palsy (Lloyd et al., 1975; Hirsch et al., 1987; Zweig et al., 1987, 1989; Jellinger, 1988; Halliday et al., 1990). Additional interest in the PPTg has been provided by the extraordinary finding of increased numbers of cholinergic 
neurons in the PPTg of schizophrenic patients (Karson et al., 1991). The data presented here indicate clearly that cholinergic neurons in the PPTg influence the activity of nigrostriatal DAcontaining neurons. It may therefore be possible to suggest that PPTg cholinergic neurons could be contributing to at least some of the symptoms of schizophrenia by driving DA neurons at source in the substantia nigra pars compacta. It will be of interest to determine in future studies exactly how mesopontine cholinergic systems might contribute to these various psychopathological disorders.

\section{References}

Adams RN, Marsden CA (1982) Electrochemical detection methods for monoamine measurements in vitro and in vivo. In: Handbook of psychopharmacology, Vol 15 (Iversen LL, Iversen SD, Snyder SH, eds), pp 1-74. New York: Plenum.

Beninato M, Spencer RF (1987) A cholinergic projection to the rat substantia nigra from the pedunculopontine tegmental nucleus. Brain Res 412:169-174.

Beninato M, Spencer RF (1988) The cholinergic innervation of the rat substantia nigra: a light and electron microscopic immunohistochemical study. Exp Brain Res 72:178-184.

Benveniste H, Hansen AT, Ottosen NS (1989) Determination of brain interstitial concentrations by microdialysis. J Neurochem 52:17411750 .

Blaha CD (1992) Electrochemical evaluation of the microenvironment surrounding microdialysis probes in vivo. In: Proceedings of the 5th International Conference on In Vivo Methods, Monitoring molecules in neuroscience (Rollema H, Westerink BHC, Drijfhout WJ, eds), pp 56-60. Meppel, The Netherlands: Krips Repro.

Blaha CD, Jung ME (1991) Electrochemical evaluation of stearatemodified graphite paste electrodes: selective detection of dopamine is maintained after exposure to brain tissue. J Electroanal Chem 310: 317-334.

Blaha CD, Lane RF (1983) Chemically moditied electrode for in vivo monitoring of brain catecholamines. Brain Res Bull 10:861-864.

Blaha CD, Phillips AG (1992) Pharmacological evidence for common mechanisms underlying the effects of neurotensin and neuroleptics on in vivo dopamine efflux in the rat nucleus accumbens. Neuroscience, in press.

Blaha CD, Coury A, Fibiger HC, Phillips AG (1990) Effects of neurotensin on dopamine release and metabolism in the rat striatum and nucleus accumbens: cross-validation using in vivo voltammetry and microdialysis. Neuroscience 34:699-705.

Bolam JP, Francis CM, Henderson Z (1991) Cholinergic input to dopaminergic neurons in the substantia nigra: a double immunocytochemical study. Neuroscience 41:483-494.

Butcher LL, Marchand R (1978) Dopamine neurons in pars compacta of the substantia nigra contain acetylcholinesterase: histochemical correlations on the same brain section. Eur J Pharmacol 52:415-417.

Clarke PBS, Pert A (1985) Autoradiographic evidence for nicotinic receptors on nigrostriatal and mesolimbic dopaminergic neurons. Brain Res 348:355-358.

Clarke PBS, Schwartz RD, Paul SM, Pert CB, Pert A (1985) Nicotinic binding in rat brain: autoradiographic comparison of $\left({ }^{3} \mathrm{H}\right)$ acetylcholine, $\left({ }^{3} \mathrm{H}\right)$ nicotine and $\left({ }^{125} \mathrm{I}\right)$ alpha-bungarotoxin. J Neurosci 5:1307-1315.

Clarke PBS, Hommer DW, Pert A, Skirboll LR (1987) Innervation of substantia nigra neurons by cholinergic afferents from pedunculopontine nucleus in the rat: neuroanatomical and electrophysiological evidence. Neuroscience 23:101 1-1019.

Damsma G, Boivert LA, Mudrick D, Wenkstern D, Fibiger HC (1990) The effects of transient forebrain ischemia and pargyline on extracellular concentrations of dopamine, serotonin and their metabolites as determined by in vivo microdialysis. J Neurochem 54:801-808.

Dunbar JS, Hitchcock K, Latimer M, Rugg EL, Ward N, Winn P (1992) Excitotoxic lesions of the pedunculopontine tegmental nucleus of the rat. II. Examination of eating and drinking, rotation, and reaching and grasping following unilateral ibotenate or quinolinate lesions. Brain Res 589:194-206.

Glowinski J, Axelrod J, Iversen LL (1966) Regional studies of catecholamines in the rat brain. IV. Effects of drugs on the disposition of 3H-norepinephrine and 3H-dopamine. J Pharmacol Exp Ther 53:3041.
Goodman-Gilman A, Goodman LS, Gilman A (1980) The pharmacological basis of therapeutics, 6th ed (Mayer SE, Melnon KL, eds). New York: Macmillan.

Gould E, Woolf NJ, Butcher LL (1989) Cholinergic projections to the substantia nigra from the pedunculopontine and laterodorsal tegmental nuclei. Neuroscience 28:611-623.

Greenfield SA, Cheramy A, Leviel V, Glowinski J (1980) In vivo release of acetylcholinesterase in cat substantia nigra and caudate nucleus. Nature 284:355-357.

Halliday GM, Gai WP, Blessing WW, Geffen LB (1990) Substance $\mathrm{P}$-containing neurons in the pontomesencephalic tegmentum of the human brain. Neuroscience 39:81-96.

Harrison JB, Woolf NJ, Buchwald JS (1990) Cholinergic neurons of the feline pontomesencephalon. I. Essential role in "wave A" generation. Brain Res 520:43-54.

Hirsch E, Graybiel AM, Duyckaerts C, Javoy-Agid F (1987) Neuronal loss in the pedunculopontine tegmental nucleus in Parkinson's disease and progressive supranuclear palsy. Proc Natl Acad Sci USA 84:59765981.

Jacobowitz DM, Goldberg AM (1977) Determination of acetylcholine in discrete regions of the rat brain. Brain Res 122:575-577.

Jellinger K (1988) The pedunculopontine nucleus in Parkinson's disease, progressive supranuclear palsy and Alzheimer's disease. J Neurol Neurosurg Psychiatry 51:540-543.

Karson CN, Garcia-Rill E, Biedermann J, Mrak RE, Husain MM, Skinner RD (1991) The brain stem reticular formation in schizophrenia. Psychiatry Res 40:31-48.

Kemp JA, Walker RJ, Woodruff GN (1977) The actions of cholinomimetics and catecholamines on rat substantia nigra neurons. Proc $\mathrm{Br}$ Pharmacol Soc 507:522.

Lacey MG, Calabresi P, North RA (1990) Muscarine depolarizes rat substantia nigra zona compacta and ventral tegmental neurons in vitro through $\mathbf{M}_{1}$-like receptors. J Pharmacol Exp Ther 253:395-400.

Lee HJ, Rye DB, Hallanger AE, Levey AI, Wainer BH (1988) Cholinergic vs. non-cholinergic efferents from the mesopontine tegmentum to the extrapyramidal motor system nuclei. J Comp Neurol 275 : $469-492$.

Lehmann J, Fibiger HC (1978) Acetylcholinesterase in the rat substantia nigra and caudate-putamen of the rat: properties and localization in dopaminergic neurons. J Neurochem 30:615-624.

Lichtensteiger W, Hefti F, Felix D, Huwyler T, Melamed E, Schlump M (1982) Stimulation of nigrostriatal neurons by nicotine. Neuropharmacology 21:963-968.

Lloyd KG, Mohler H, Heitz PH, Bartholini G (1975) Distribution of choline acetyltransferase and glutamate decarboxylase within the substantia nigra and in other brain regions from control and Parkinsonian patients. J Neurochem 25:789-795.

Mesulam M-M, Geula C, Bothwell MA, Hersh LB (1989) Human reticular formation: cholinergic neurons of the pedunculopontine and laterodorsal tegmental nuclei and some cytochemical comparisons to forebrain cholinergic neurons. J Comp Neurol 281:611-633.

Nastuk MA, Graybiel AM (1991) Pharmacologically defined M1 and M2 muscarinic cholinergic binding sites in the cat's substantia nigra: development and maturity. Dev Brain Res 61:1-10.

Parker GC, Rugg EL, Winn P (1991) Cholinergic stimulation of substantia nigra: abolition of carbachol-induced eating by unilateral 6-hydroxydopamine lesion of nigrostriatal dopamine neurons. Exp Brain Res 87:597-603.

Paxinos G, Watson C (1986) The rat brain in stereotaxic coordinates, 2nd ed. New York: Academic.

Pellegrino LJ, Pellegrino AS, Cushman AJ (1979) A stereotaxic atlas of the rat brain, 2d ed. New York: Applcton-Century-Crofts.

Pfaus JG, Damsma G, Nomikos GG, Wenkstern DG, Blaha CD, Phillips AG, Fibiger HC (1990) Sexual behavior enhances dopamine transmission in the male rat. Brain Kes 530:345-348.

Rugg EL, Dunbar JS, Latimer M, Winn P (1992) Comparison of the neurotoxic properties of various excitotoxins in the pedunculopontine tegmental nucleus of the rat, with particular reference to the loss of immunohistochemically identified cholinergic neurons. Brain Res 589: 181-193.

Scarnati E, Hajdu F, Pacitti, Tombol T (1988) An EM and Golgi study on the connection between the nucleus tegmenti pedunculopontinus and the pars compacta of the substantia nigra in the rat. J Hirnforsch 29:95-105.

Semba K, Reiner PB, Fibiger HC (1990) Single cholinergic mesopon- 
tine tegmental neurons project to both the pontine reticular formation and the thalamus in the rat. Neuroscience 38:643-654.

Steriade M, Llinas RR (1988) The functional states of the thalamus and the associated neuronal interplay. Physiol Rev 68:649-742.

Steriade M, Datta S, Pare D, Oakson G, Curro'Dossi R (1990) Neuronal activities in brain-stem cholinergic nuclei related to tonic activation processes in thalamocortical systems. J Neurosci 10:25412559.

Taha EB, Redgrave P (1980) Neuroleptic suppression of feeding and oral stereotypy following microinjection of carbachol into substantia nigra. Neurosci Lett 20:357-361.

Taylor P (1980) Anticholinesterase agents. In: The pharmacological basis of therapeutics, 6th ed (Gilman AG, Goodman LS, Gilman A, eds; Mayer SE, Melmon KL, associate eds), pp 100-119. New York: Macmillan.

Ungerstedt $U$ (1984) Measurement of neurotransmitter release by intracranial dialysis. In: Measurement of neurotransmitter release in vivo (Marsden CA, ed), pp 81-105. New York: Wiley.

Winn P (1990) Cholinergic stimulation of substantia nigra: effects on feeding, drinking and sexual behaviour in the male rat. Psychopharmacology 104:208-214.
Winn P, Redgrave P (1979) Feeding following microinjection of cholinergic substances into substantia nigra. Life Sci 25:333-338.

Winn P, Redgrave P (1981) Dose-dependent feeding in the rat following substantia nigra acetylcholinesterase blockade. Eur J Pharmacol 76:421-425.

Winn P, Farrell A, Maconick A, Robbins TW (1983) Behavioural and pharmacological specificity of the feeding elicited by cholinergic stimulation of the substantia nigra in the rat. Behav Neurosci 97:794 809.

Woolf NJ, Butcher LL (1986) Cholinergic systems of the rat brain. III. Projections from the pontomesencephalic tegmentum to the thalamus, tectum, basal ganglia, and basal forebrain. Brain Res Bull 16: 603-637.

Zweig RM, Whitehouse PJ, Casanova MF, Walker LC, Jankel WR, Price DL (1987) Loss of pedunculopontine neurons in progressive supranuclear palsy. Ann Neurol 22:18-25.

Zweig RM, Jankel WR, Hedreen JC, Mayeux MD, Price DL (1989) The pedunculopontine nucleus in Parkinson's disease. Ann Neurol $26: 41-46$. 